\begin{tabular}{c} 
Volume and Issues Obtainable at Center for Sustainability Research and Consultancy \\
Sustainable Business and Society in Emerging Economies \\
ISSN: $2708-2504$ (E): 2708-2172 \\
Volume 1: No 1, June 2020 \\
CSRᄃ \\
Journal homepage: $\underline{\text { ww.publishing.globalcsrc.org/sbsee }}$ \\
\hline
\end{tabular}

\title{
Challenges Faced by the Repatriates and their Subsequent Impact on Repatriates' Satisfaction \\ ${ }^{1}$ Muhammad Shaukat Malik, ${ }^{2}$ Usman Farooq, ${ }^{3}$ Famya Khalid
}

${ }^{1}$ Director and Dean, Institute of Banking and Finance, Bahauddin Zakariya University, Multan,Pakistan. Shoukatkatmalik@bzu.edu.pk

${ }^{2}$ Visiting Faculty, Institute of Banking and Finance, Bahauddin Zakariya University, Multan,Pakistan. usmanfarooquf@gmail.com

${ }^{3}$ MS Scholar, Department of CABB, University of Agriculture, Faisalabad, Pakistan, famyakhalid5@gmail.com

\begin{tabular}{|c|c|}
\hline ARTICLE DETAILS & ABSTRACT \\
\hline $\begin{array}{l}\text { History } \\
\text { Revised format: May } 2020 \\
\text { Available Online: June } 2020\end{array}$ & \multirow{3}{*}{$\begin{array}{l}\text { Objective: Through decades repatriation has been the most ignored } \\
\text { and a problematic phase of the Expatriate Management Cycle } \\
\text { (EMC). Expatriates when returning back to their home country are } \\
\text { referred as Repatriates and this returning phase is known as } \\
\text { Repatriation phase of the Expatriate Management Cycle. This } \\
\text { Repatriation phase is mainly the unplanned stage where } \\
\text { organizational managers make the mistake. They certainly believe } \\
\text { that the repatriates are returning back to their home and wrongly } \\
\text { assumes that there will be no complications or challenges for these } \\
\text { repatriates on their arrival back to home country. This strategic lack } \\
\text { results in the immense dissatisfaction of these repatriates soon after } \\
\text { arrival to the home county. Our aim is to provide a detailed study on } \\
\text { the process of repatriation by identifying the challenges that are } \\
\text { faced by the repatriates on their arrival to the home country and to } \\
\text { oversee their subsequent impact on their job performance. } \\
\text { Methodology: Data was collected through primary means using } \\
\text { convenience sampling method through various organizations and of } \\
300 \text { respondents } 186 \text { were filtered out to be analyzed using different } \\
\text { statistical techniques on SPSS. } \\
\text { Result: There exist a significant negative relationship between all } \\
\text { the identified challenges faced by the repatriates and their job } \\
\text { satisfaction level } \\
\text { Implication: At the end of the research some recommendations } \\
\text { were also proposed for the organizational managers to overcome } \\
\text { these challenges. This piece of research can not only be used by the } \\
\text { researchers for their research work but can also be based by the } \\
\text { organizational managers to formulate their repatriation strategies.l }\end{array}$} \\
\hline $\begin{array}{l}\text { Keywords } \\
\text { Repatriation, Expatriate } \\
\text { Management Cycle, Predictors } \\
\text { of Repatriation, Repatriates }\end{array}$ & \\
\hline & \\
\hline & NonCommercial 4.0 \\
\hline
\end{tabular}


Corresponding author's email address: usmanfarooquf@gmail.com

Recommended citation: Malik M.S., Farooq U., \& Khalid F., (2020). Challenges Faced by the Repatriates and their Subsequent Impact on Repatriates' Satisfaction. Sustainable Business and Society in Emerging Economies, 1(1), 1-11

\section{Introduction}

Due to the globalization today, organizations are challenged to go global by expanding their businesses in the global markets and gaining the international knowledge and expertise. For this reason there is an intense demand in the organizations to send their employees for the international ventures. An Expatriate is a person who is temporarily residing or working in a country or culture other than his culture of origin (Noe, 2013). And these expatriates when returning back to the home country are called repatriates. This Repatriation phase of the expatriate management cycle is the most key troublesome area for the employers in the global companies because knowingly the organizations do not have any properly formulated procedures and plans for these returning repatriates that often cause moment of high anxiety and tension for these returnees (Yeaton \& Hall, 2008).

Despite of facing all the troubles and challenges organizations have not widely accepted the repatriation program in there international human resource systems. They seldom understand the need to initiate any special programs in order to prepare their returning employees to get readjusted back in their home culture. The returning expatriates are assumed to re-enter back into their home country and culture so no special training programs or readjustment strategies are planned by the employers. Due to this strategic lack in handling the readjustment process for the repatriates and not being able to formulate bona fide repatriation plans including career paths for the returning expats, leads these repatriates to underutilization of their knowledge and high ineffectiveness.

In terms of particularly Pakistan this area of international human resource management has almost been untapped. There exists lots of space to see that how these repatriates are being handled in Pakistan. Along with that strategic importance of the repatriation phase of the expatriate management cycle will be seen. Our research will have a two fold significance. Firstly it will be beneficial for the academic sector and secondly it will be beneficial for the organizational managers to know the strategic importance of repatriation process.

\subsection{Defining Repatriation Phase}

Sending of the employees on international assignments should not be seen as a one way task, rather the returning phase of the Expatiate Management Cycle should also be focused by the organization. Organizations generally focus in planning the expatriation process for their employees that are being sent to some international assignment and usually skip any arrangements for their return back to the home country. Because of this avoidance paid by the organizational managers to the repatriation process causes the repatriates to face numerous challenges on their arrival back in the host country which ultimately results in job dissatisfaction. Organizations must emphasize on devising policies and procedures to untapped the learnt knowledge and expertise from these repatriates in their international exposure. Repatriates gain knowledge and skills from their international experience and transfers this gained experience back in home organization when they return back to their home country (Doherty, Richardson, and Thorn, 2013).

\subsection{Identifying the Challenges Faced by the Repatriates}

Organizational managers plan the whole EMC, they formulate strategies in order to plan and execute training and facilitating programs for each of the stage of cycle but they knowingly ignore the last repatriation phase and believe that there will be no complications attached to this phase as the expatriates are to return back to their own country and assumes that they will be comfortable to re-adjust in their home country. (M. Jitendra, 2011). 
The Repatriation Phase is the key issue for the employees in global companies because the organizations management usually has no proper formulated procedures and plans for the returning expatriates who often cause a moment of high anxiety and several problems for these expatriates (Yeaton and Hall, 2008). Success of expatriation cycle depends upon how well the repatriation phase is initiated and completed. In the repatriation phase employees return back to their primary country and often face with innumerable complications like reverse cultural shock and require lots of assistance and training for their smooth adjustment to the home country (Kjerfve and McLean, 2012)

Repatriates may suffer in the readjustment in to the home organization at the time of arrival from the global venture. Certain phenomenon like culture and organizational environment may have changed. Even the whole organizational or cultural dynamics could have been changed during the period of International Assignments. Policies of the organizations, internal structures of the company, staff or even management might have been changed by the duration repatriate returns from their international assignment which could result in creating readjustment issues (E. A. Kim, 2007).

\subsection{Reverse Cultural Shock}

Reverse cultural shock may effects different individuals with different intensity. Often it hits greatly to the people who have to make immense changes in their behavior during their adjustment phase at overseas assignments. (Gaw, 2000). Such repats on their arrival back to the home culture have to revert back to their actual state of behavior for which they have to exert with double effort and commitment as compared to that exerted, at the time of adjustment in host culture (Stroh, Gregersen and Black, 2000).

Reverse cultural shock impacts adversely on the repatriates as they lose their social contact from their surroundings and get cut off from the communal contact from their native culture, people and colleagues; and suffer in the readjustment phase when they have to return to their home country and have to readjust themselves in the home culture. At that moment reverse cultural shock hinders their readjusting phase and impact adversely on the repatriates. Its impact may be of much unexpected content (Baruch, Steele and Quantrill, 2002).

\subsection{Repatriates Readjustment}

An effective management's involvement is required for the repatriates in adjusting back in their home country. Their social networks are required to be re-established. Repatriates need several trainings and technological learning upon repatriation for proper readjustment (Baruch et al., 2002; Vidal, Valle, Aragon and Brewster, 2007). Moreover upon re-entry to the home culture repatriates and their families may take a long up to one year to regulate back in normal routine of their organizations (Linehan and Scullion, 2002). According to another study repatriates adjustment is a lengthy process and can take up to a year in order to redeveloping their social networks (Jassawalla and Sashittal, 2009).

Repatriation phase is more problematic for the female officials on international assignments (Stroh, Gregersen, \& Black, 2000). In readjustment stage females often have to face several stresses because they are assumed to assist their families to readjust back into the home culture and for that reason they face difficulties in their professional readjustment (Linehan and Scullion, 2002). According to another study repatriates were able to identify several factors as a potential source of mediators that influence the readjustment stage. Those factors were the time span that a repatriate has invested in to the international assignment, the distance to which repatriate has gone from the home culture for the assignment, age of international assignment and the attributes of the job assigned (Suutari and Valimaa, 2002).

Repatriates are the employees on which the company invests as much as three to five times more than on a regular employee. Repatriates are the source of updated knowledge, skills and expertise for the organization. But most of the time the acquired knowledge remains untapped due to the lack of policies and procedures by the home companies that hinders the readjustment of the employees into the 
organization and results in high dissatisfaction of the repatriates and increase in turnover ratio (Kjerfve and Gary, 2011).

\subsection{Family Adjustment}

According to a cross cultural study held by the authors of Unites States suggested that expatriates and their families on the termination of their international tasks when return back to the home culture had to face several stressors in the form of cultural and environmental settlement. These stressors are the biggest challenge which acts as a hurdle in the adjustment process especially for the families of these repatriates. (Haslberger et al., 2008). At that time it is not only the repatriate who may suffer and face complications in adjustment but his family is also a stakeholder in this process. Spouses of the repatriates on returning back to the home culture suffers in adjusting back into the home environment. If she is a working lady she might also have face her job related issues along with the personal adjustment problems. These expected issues are not particularly discussed in the repatriation phase of EMC (Avril and Magnini, 2007).

If such family issues are not properly planned by the organizational managers they may lead to dissatisfaction of the repatriate which might lead him to switch his company. And the organization may not be able to enjoy with the total benefits that it could attain from the acquired knowledge gained by repatriates (M.C. Bolino, 2007).

\subsection{Career Management}

Organizational focus should be on the formulation of the international assignments, attractiveness of the training programs, quality of the compensation and career opportunities offered on return to the repatriates on the termination of the international assignment (McEvoy and Buller, 2013). Turnover ratio in repatriates is more than the other employees. It is due the reason that if the repatriates are unsatisfied with the organizational efforts they achieve on return from the global assignments in terms of their career development and future career aspect they prefer to leave the organization and seek new jobs for them (Vidal et al., 2007a).

Repatriates turnover is one of the major issues for the multinational organizations who are undergoing the repatriation process. Multinationals spend lots of amount on the repatriates and if they switch their jobs this can be of much loss for the organization. Therefore the organizations must put efforts towards formulating attractive career paths and career development opportunities for these repatriates so they could settle back in the organizations and could remain motivated (Lazarova and Cerdin, 2007).

\subsection{Job Placement}

Organizations can never hide themselves away from reinforcing the repatriation practices. Organizational managers have to provide new job placements and opportunities better than those offered to the expatriates before the international experience. They are also required to create the new career paths for the repatriates where they can best utilize their newly acquired knowledge, skills and expertise which will not only enhance the motivational level of the repatriates but also will enhance the organizational performance (Kjerfve and Gary, 2011). Organizational Management should pay attention on the repatriation process carefully by offering them such new job placements on their return the home country that the skills and expertise acquired by these repatriates could be properly procured and organizational learning could be intensified (Barakat and Moussa, 2014). If the organizations do not plan proper career paths for the repatriates it may turn the repatriates to dissatisfaction on their arrival back to the home country (Bossard and Peterson, 2005).

\subsection{Societal Changes}

International experience can distance the returning expatriates socially. Their stay in the host country can result in social gaps for the repatriates. The social relations and interactions may get disturbed due to the long span of time the repatriates might find themselves in to the state of isolation. This creates a high 
moral lapse and eventually results in dissatisfaction of the repatriates (Martin, 1984). It is the organizational management who devise such policies that keeps the repatriates motivated towards their jobs. If the organization fails to provide the required support to the repatriates, in dealing up with the challenges like social readjustment, this could result in dissatisfaction of the repatriates (Suutari and Tornikoski, 2001)

\subsection{Job Satisfaction}

Satisfaction of the employees acts to be a key determinant of organizational success. It has been researched and concluded many a times that a satisfied employee will act to be more beneficial and productive to an organization than an employee who is less satisfied with the organizational practices. A dis-satisfied employee tends to be less motivated towards the organizational workings and fails to pay his best concern towards the assigned tasks from the organizations (Spector, 1997)

The above identified six challenges i.e. the societal issues, reverse cultural shock, career management issues, job placement issues, repatriates readjustment issues and family adjustment issues seems to have an adverse impact on repatriate's job satisfaction on their arrival back to the home country. Most of the firms do not properly handle their repatriates and ultimately these repatriates get dissatisfied with the passage of time and eventually goes for leaving their organizations. In such cases firms usually have to bear heavy losses not only in terms of capital invested on these repatriates during their international assignments but also in terms of a loss of qualified and competent human capital that could have been a significant resource to the organization who has the international exposure and experience.

Therefore it is the prime responsibility of the organizational managers to retain these repatriates by keeping them motivates and satisfied with the organizational culture.

\section{HYPOTHESIZED THEORETICAL MODEL}

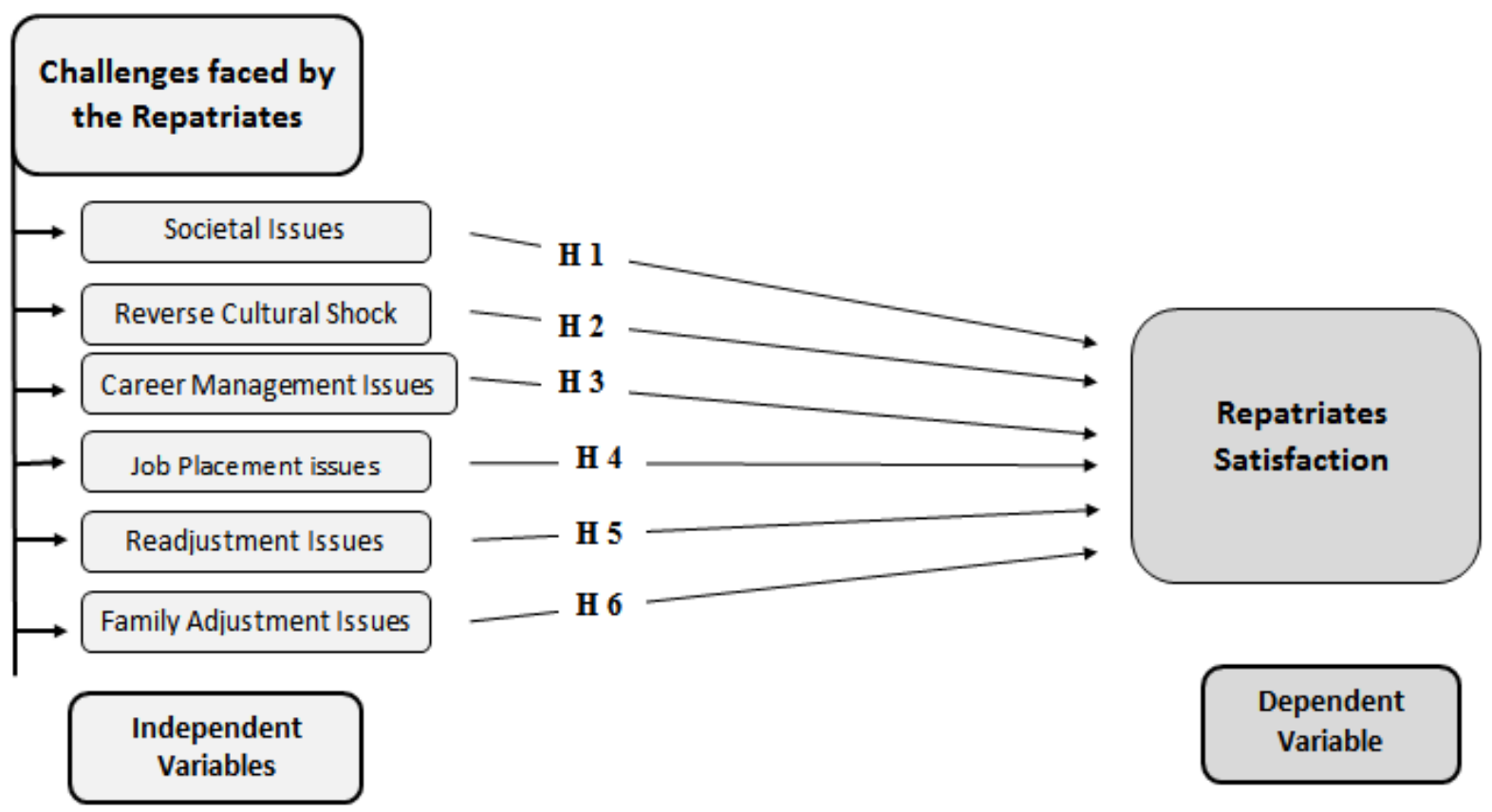

Figure 1: Hypothesized Theoretical Model

\section{HYPOTHESIS}

H 1: Societal Issues have a negative relationship with Repatriates Job Satisfaction. 
H 2: Reverse Cultural Shock has a negative relationship with Repatriates Job Satisfaction.

H 3: Career Management Issues have a negative relationship with Job Satisfaction

H 4: Job Placement Issues have a negative relationship with Repatriates Job Satisfaction.

H 5: Repatriates Readjustment Issues has a negative relationship with Job Satisfaction.

H 6: Family Adjustment issues have a negative relationship with impact on Job Satisfaction.

\section{Research Methodology}

Data for the research work has been collected through secondary and primary means of data collection. The topic we are conducting research on has been very less explored in Pakistan so we opt a semi structured way of interview conduction in order to get the clear dimensions of the topic, as they will allow us to invade into the area of our interest and get the answers of the uncertainties that we have in our research topic. Furthermore, the semi structured interviews act to be instrumental in establishing a piece of academic research that will nourish the concepts and views about the interest area.

For our research work we used a set of close ended questionnaire to accumulate the answers gained from the respondents. Questionnaire we used was 5-point likert scaled and was adopted. It was then tested with Cronbach's alpha test to check its reliability to attain error free results at the end of the research. In our research secondary data was collected through several published journals, various articles, electronic books and through various researches that have been conducted in different parts of the world. Further the informative material provided by my mentor Mr. Dr. Shaukat Malik who is a world renowned educationalist residing in Pakistan as a dean of institute of banking and finance, Bahauddin zakariya university was also considered and incorporated.

A Sum of total 300 questionnaires was dispersed and of them 186 were processed. Few of them were rejected on the basis of impropriate or incomplete filling while others were declined due to the reason that individuals were not residing in Pakistan. In order to maintain the global factor constant individuals (repatriates) only from Pakistan were appraised for the research work. For the analysis and coding of the collected raw data, SPSS (Statistical package of social sciences) was used and several techniques like factor analysis and correlations were applied. The reliability of questionnaire was checked by Cronbach's alpha test.

\section{Findings, Analysis, Discussions and Interpretation}

Table 1: Case Processing Summary and Reliability Statistics

Case Processing Summary

\begin{tabular}{|c|c|c|c|c|c|c|}
\hline & & $\mathbf{N}$ & $\%$ & & & \\
\hline \multirow[t]{3}{*}{ Cases } & Valid & 186 & 100.0 & \multicolumn{3}{|c|}{ Reliability Statistics } \\
\hline & Excluded $^{\mathrm{a}}$ & 0 & .0 & $\begin{array}{l}\text { Cronbach's } \\
\text { Alpha }\end{array}$ & $\begin{array}{l}\text { Cronbach's Alpha Based } \\
\text { on Standardized Items }\end{array}$ & $\mathrm{N}$ of Items \\
\hline & Total & 186 & 100.0 & .786 & .813 & 4 \\
\hline
\end{tabular}

List wise deletion based on all

variables in the procedure. 
The Reliability Statistics shows the Cronbach's Alpha Result for the used questionnaire. The results show that Cronbach's Alpha value comes out to be 0.786 which is much more than the minimum required value of 0.70 . This value of 0.786 depicts that questionnaire is $78 \%$ optimal and internally consistent and highly reliable. Therefore we directly move ahead towards the factors analysis for the research data obtained

Table 2: Factor Analysis and KMO

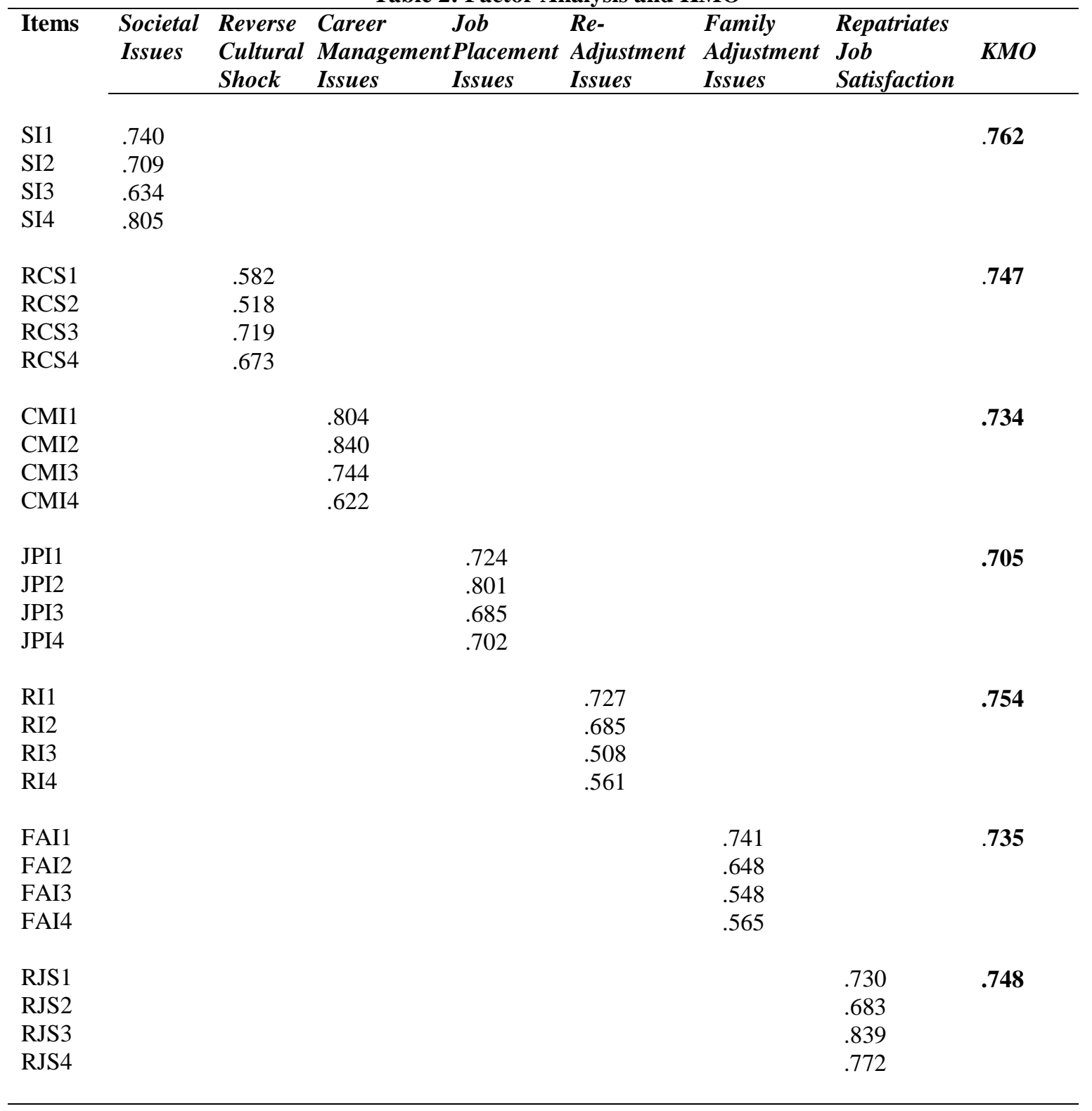

\section{Interpretation}

The table 2 shows the Factor Analysis and Kaiser-Meyer-Olkin (KMO Test). As we know if the value of $\mathrm{KMO}$ is greater than 0.60 we can move to further factor analysis. Here the table 2 depicts that KMO of Societal Issues is 0.762 , KMO of Reverse Cultural Shock is 0.747, KMO of Career Management Issues is 0.734 , KMO of Job Placement Issues is 0.705 , KMO of Readjustment Issues is 0.754, KMO of Family Adjustment Issues is 0.735 and KMO of Repatriates Job Satisfaction is 0.748 .

Here all the values of KMO are greater than 0.60 which means that we can further go for factor analysis test. Other values in the table 2 shows that the factor analysis of each item of the variable is greater than 0.50 and hence no item of the variable is left behind and all the loading items of the variables are considered for the further research. 
Correlations

Table 3: Correlation Analysis

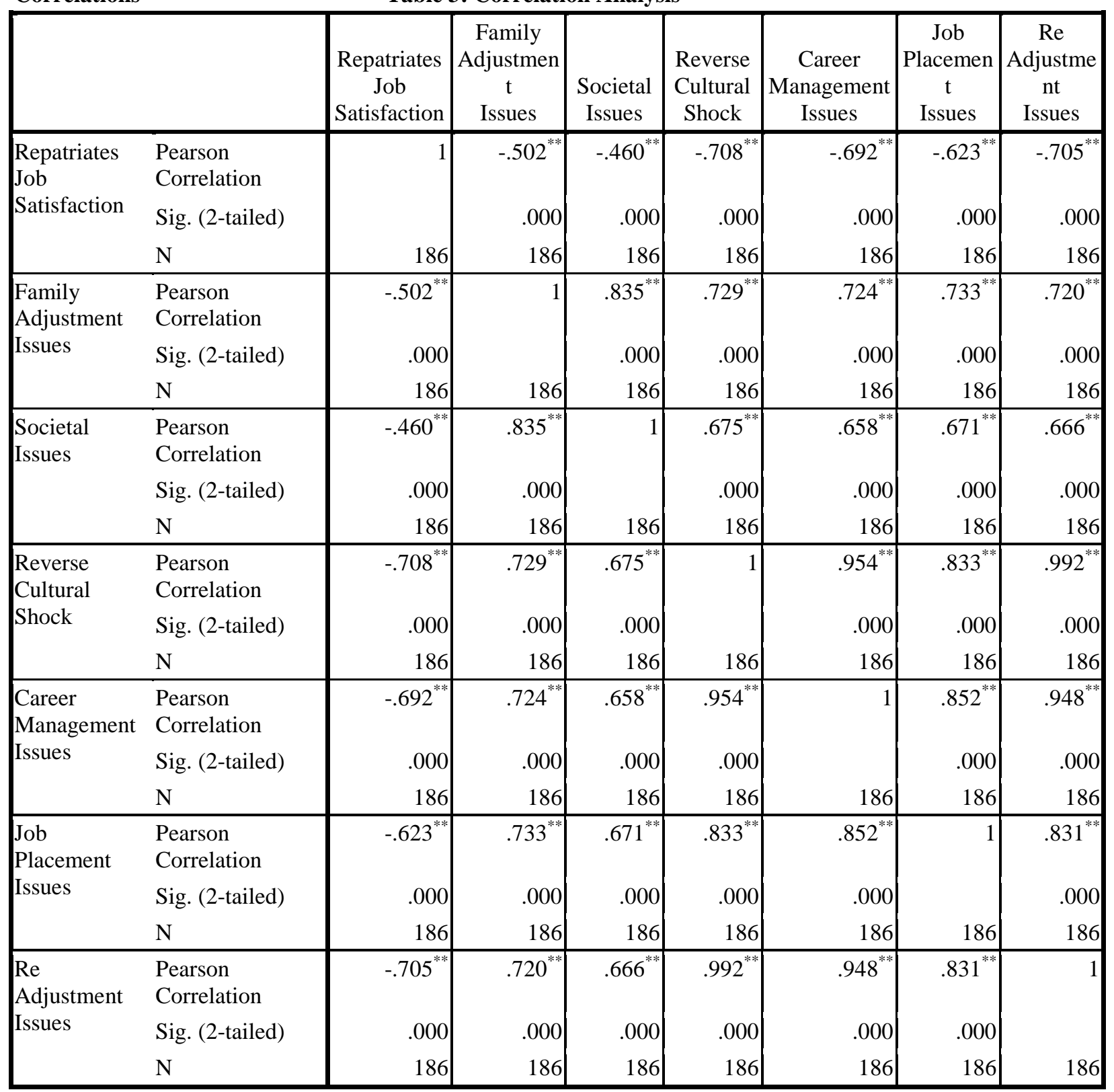

**. Correlation is significant at the 0.01 level (2-tailed).

\section{Interpretation}

Table 3 shows a significant negative relationship between all the independent and dependent variables which are discussed separately below. The relationships in the correlation analysis show that there exists a significant and negative relationship between repatriates job satisfaction and the six identified dependent variables. Higher the degree of family adjustment issues, societal issues, reversal cultural issues, career management issues, job placement issues and the readjustment issues faced by the repatriates lower will be their satisfaction level towards their job. Likewise lower the degree of issues faced by the repatriates higher will be their satisfaction level towards job.

\section{Hypothesis 1}

Societal Issues has a negative relationship with Repatriates Job Satisfaction.

Table 3 shows that exists a negative and significant relationship between job satisfaction and societal issues with a value of -0.460 . 


\section{Thus Hypothesis 1 is accepted}

That is, higher the intensity of the societal challenges faced by the repatriates lower will be their level of satisfaction towards their jobs

\section{Hypothesis 2}

Reverse Cultural Shock has a negative relationship with Repatriates Job Satisfaction.

Table 3 shows correlation between repatriates job satisfaction and reverse cultural shock is found to be negative and significant with a value of -0.708

Thus Hypothesis 2 is accepted

That is, higher the intensity of the reverse cultural shock faced by the repatriates lower will be their level of satisfaction towards their jobs

\section{Hypothesis 3}

Career Management Issues have a negative relationship with Job Satisfaction

Table 3 shows that exists a negative and significant relationship between job satisfaction and Career Management issues with a value of -0.692

Thus Hypothesis 3 is accepted

That is, higher the intensity of the career management issues faced by the repatriates lower will be their level of satisfaction towards their jobs

\section{Hypothesis 4}

Job Placement Issues have a negative relationship with Repatriates Job Satisfaction.

Table 3 shows correlation between repatriates job placement issues and their job satisfaction is found to be negative and significant with a value of -0.623

Thus Hypothesis 4 is accepted

That is, higher the intensity of the Job placement issues faced by the repatriates lower will be their level of satisfaction towards their jobs

\section{Hypothesis 5}

\section{Repatriates Readjustment Issues has a negative relationship with Job Satisfaction.}

Table 3 shows that there exists a negative and significant relationship between job satisfaction and Repatriates Readjustment issues with a value of -0.705

\section{Thus Hypothesis 5 is accepted}

That is, higher the intensity of the readjustment issues faced by the repatriates lower will be their level of satisfaction towards their jobs

\section{Hypothesis 6}

\section{Family Adjustment issues have a negative relationship with impact on Job Satisfaction.}

Table 3 shows correlation between repatriates family adjustment issues and their job satisfaction is found to be negative and significant with a value of -0.502

\section{Thus Hypothesis 6 is accepted}

That is, higher the intensity of the family adjustment faced by the repatriates lower will be their level of satisfaction towards their jobs. This can be seen from all the above interpretations and analysis tests that all the proposed hypothesis of our research are found to be accepted and thus shows their certainly exists a negative relationship between the dependent and independent variables

\section{Recommendations}

The organizational managers must develop the proper repatriation strategies. Organizations must arrange pre-return trainings for the repatriates and their families so they may not have to suffer on their arrival 
back to the home country. Proper career opportunities and job placement strategies for the repatriates should be created and the arrangements for the facilitation of their families should be emphasized by the organizational managers on priority. They must also initiate knowledge seeking sessions so that the knowledge gained by the repatriates could be extracted and used for the growth of the organizations.

This will not only enhance the organizational productivity but will also create a sense of satisfaction in repatriates. Repatriates will consider themself as a valuable asset to the organization which ultimately will enhance their satisfaction towards organization. In sum this could be said that higher the organizational emphasis is on the repatriation phase of the expatriate management cycle lesser will be the challenges faced by the repatriates on their arrival to the home country.

\section{Limitations}

Our research work conducted has several limitations which are as:

1) Data was collected was only from Pakistan

2) Topic was new and the field was less explored so it was quite difficult to find the target population and for that reason convenience sampling method was used for collecting data

3) Research was not sector specific. Repatriates from all the sectors were considered for data collection

\section{Conclusion}

This study was conducted to identify the challenges that the repatriates may face on their arrival to the home country after the successful completion of their international assignments. The issues faced by the repatriates were seen to be the job placement issues, reverse cultural shock, career management issues, societal issue, readjustment issues of repatriates, and family adjustment issues. Repatriates not only suffer with the challenges faced in their organization and work place but also had to suffer with the external factors on their arrival back. These identified challenges faced by the repatriates were then measured through the primary means of research and was analyzed that all these identified challenges were having a significant negative relationship with the repatriates satisfaction.

Organizational managers must take timely and essential steps like development of strategies for the repatriates, pre-return trainings, making compensation packages, organizing sessions for the repatriates so the gained knowledge could be extracted from them and can be transferred to re rest of the organization. Organization must also take steps for the readjustment of these repatriates and their families so they could adjust back into the home country easily without taking extra pressure. Higher the emphasis is on the repatriation phase of the expatriation management cycle by the organizational managers lesser will be the chance that the returning repatriates will face challenges on their arrival. And likewise lesser the challenges are faced by the repatriates on their arrival back to the home country; Higher will be their satisfaction level and so will be their performance. Hence, this supports the idea that the repatriation phase of expatriation management cycle, which has been ignored through decades, is equally crucial as the expatriation phase. Managers must pay equal focus and attention in devising repatriation policies and training programs so the challenges faced could be minimized and subsequently the satisfaction level of the repatriates could be raised.

\section{Directions for Future}

Human resources is an area which is not very mature in Pakistan so there exists a great prospect of research particularly in the area of repatriation no or very less work has been done in Pakistan. So our work can be taken as a base to identify more challenges faced by the repatriates. And these identified variables can be researched and tested through quantitative means research in future. Furthermore our work can be utilized by the organizational managers to make strategies for the returning repatriates. This piece of research can also be used by the researchers to check the global impact of this idea in different parts of the world. 
References

Noe, R.A. (2013). Employee training and development (6th ed.). New York: McGraw-Hill.

Yeaton, K., \& Hall, N. (2008). Expatriates: Reducing failure rates. Journal of Corporate Accounting \& Finance, 75-78.

Miranda, J. C. (2009). An exploratory research On learning styles of expatriates in Malaysia. Unitar EJournal, 5(1), 82-101.

Doherty, N., Richardson, J., \& Thorn, K. (2013). Self-initiated expatriation and self-initiated expatriates: Clarification of the research stream. Career Development International, 18(1), 97-112.

Jitendra, M. (2011). Repatriation. Advances In the Management, 4(1), 7-9

Stroh, L. K., Gregersen, H. B., \& Black, J. S. (2000). Triumphs and tragedies: expectations and commitments upon repatriation. International Journal of Human Resource Management, 11(4), 681-697.

Baruch, Y., Steele, D. J., \& Quantrill, G. A. (2002). Management of expatriation and repatriation for novice global player. International Journal of Manpower, 23(7), 659-671.

Gaw, K. F. (2000). Reverse culture shock in students returning from overseas. International Journal of Intercultural Relations, 24(1), 83-104.

Vidal, M. E. S., Valle, R. S., Aragón, M. I. B., \& Brewster, C. (2007). Repatriation adjustment process of business employees: Evidence from Spanish workers. International Journal of Intercultural Relations, 31(3), 317-337.

Linehan, M., \& Scullion, H. (2002). Repatriation of European female corporate executives: an empirical study. International Journal of Human Resource Management, 13(2), 254-267.

Jassawalla, A. R., \& Sashittal, H. C. (2009). Thinking strategically about integrating repatriated managers in MNCs. Human Resource Management,48(5), 769-792.

Suutari, V., \& Välimaa, K. (2002). Antecedents of repatriation adjustment: New evidence from Finnish repatriates. International Journal of Manpower,23(7), 617-634.

Haslberger, A., \& Brewster, C. (2008). The expatriate family: An international perspective. Journal of Managerial Psychology, 23(3), 324-346.

Avril, A. B., \& Magnini, V. P. (2007). A holistic approach to expatriate success. International Journal of Contemporary Hospitality Management,19(1), 53-64.

Bolino, M. C. (2007). Expatriate assignments and intra-organizational career success: Implications for individuals and organizations. Journal of international business studies, 38(5), 819-835.

McEvoy, G. M., \& Buller, P. F. (2013). Research for practice: The management of expatriates. Thunderbird International Business Review, 55(2), 213-226.

Lazarova, M. B., \& Cerdin, J. L. (2007). Revisiting Repatriation. Journal of International Business Studies, 38, 404-429.

Barakat, A., \& Moussa, F. (2014). Variables influencing expatriate learning and organizational learning. Competitiveness Review, 24(4), 275-292

Bossard, A., \& Peterson, R. B. (2005). The repatriate experience as seen by American expatriates. Journal of World Business, 40, 9-28.

Martin, K, A. (1984). Repatriation transitions: Psychological preparedness, cultural identity, and attributions among American managers.International Journal of Intercultural Relations, 25(2), 109-123.

Suutari, V., \& Tornikoski, C. (2001). The challenge of expatriate compensation: The sources of satisfaction and dissatisfaction among expatriates. International Journal of Human Resource Management, 12(3), 389-404.

Spector, P. E., "Job Satisfaction: Applications, Assessment, Causes and Consequences" (1997).Psychology Faculty Publications. Paper 554 